\title{
Current Understanding on the Role of Cell Cycle Regulators in Neuroblastoma Cell Differentiation
}

\author{
Veronica Partridge ${ }^{1}$, Michaela Sousares ${ }^{1}$, Zhenze Zhao ${ }^{1}$, Liqin Du ${ }^{1 *}$ \\ ${ }^{1}$ Department of Chemistry and Biochemistry, Texas State University, \\ San Marcos, Texas.
}

*Corresponding to: Liqin Du, PhD, Department of Chemistry and Biochemistry, Texas State University, 601 University Drive, San Marcos, Texas 78666, (512) 245-1038. Email: I_d141@txstate.edu.

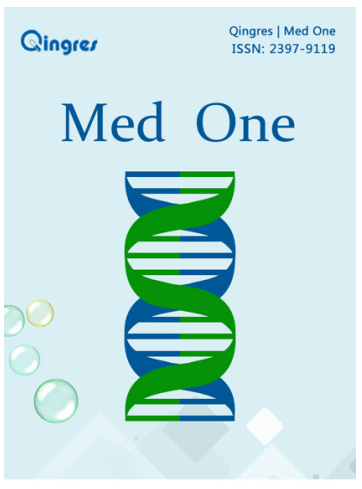

http://mo.qingres.com

\section{GOPEN ACCESS}

DOI: $10.20900 / \mathrm{mo} .20170010$

Received: March 06, 2017

Accepted: May 14, 2017

Published: June 25, 2017

Copyright: $\odot 2017$ Cain et al. This is an open access article distributed under the terms of the Creative Commons Attribution License, which permits unrestricted use, distribution, and reproduction in any medium, provided the original author and source are credited.

\begin{abstract}
Neuroblastoma is a pediatric cancer that arises from neural crest cells failing to differentiate into mature neuronal cells. Differentiation therapy is one of the effective approaches to treat high-risk neuroblastoma. Developing new differentiation agents that can be used to treat neuroblastoma, especially for those resistant to currently available differentiation agents, is a major task in the field of neuroblastoma research. It has been known that neuroblastoma cell differentiation is tightly coupled with cell cycle progression. More importantly, multiple cell cycle regulating proteins have been shown to play critical roles in modulating neuroblastoma differentiation process, suggesting the potential of targeting these cell cycle regulators for differentiation therapy. Here we review the cell cycle regulators that have been recognized to function as independent regulators of cell differentiation, including cyclindependent kinase 4 , cyclin D1, and the Cip/Kip family proteins, with a focus on their involvement of the differentiation of neuroblastoma cells. We also discuss the potential and approaches of discovering new cell cycle-regulating differentiation agents from common sources of anti-cancer agents such as extracts from plants.
\end{abstract}

Keywords: Cell cycle; neeuroblastoma; cell differentiation; differentiation therapy

\section{INTRODUCTION}

Neuroblastoma is a spectrum of pediatric neuroblastic tumors that affects more than 700 children in the United States per year ${ }^{[1,2]}$. It is a type of solid tumor cancer that arises from neural crest cells of the sympathetic nervous system that fail to differentiate into mature neurons ${ }^{[3]}$. Differentiation therapy is one major approach to treat neuroblastoma ${ }^{[4]}$. One major advantage of differentiation therapy over 
traditional chemotherapies is the potential low nonspecific toxicity because, theoretically, differentiation agents would not affect mature functional cells. 13-cis-retinoic acid is the most effective differentiation agent available to treat neuroblastoma, and it is currently used as standard-of-care for post remission maintenance therapy in high-risk neuroblastoma patients ${ }^{[5]}$, highlighting the importance of differentiation therapy in neuroblastoma treatment. Studies have shown that retinoic acid improves survival rate of neuroblastoma patients but not significantly ${ }^{[6]}$, indicating resistance to retinoic acid in certain neuroblastomas and the needs of developing new differentiation agents to treat the retinoic acid-resistant neuroblastomas. Developing new classes of differentiation agents relies on better understanding of the molecular mechanisms that control neuroblastoma cell differentiation. Studies have indicated that cell cycle regulators play key roles in modulating neuroblastoma cell differentiation processes, suggesting the possibility of targeting cell cycle-regulating pathways to induce neuroblastoma cell differentiation. Here, we review recent advances in understanding the role of cell cycle regulators in cell differentiation with a primary focus on regulators that have been studied in neuroblastoma cell differentiation, and discuss the potential of targeting cell cycle progression for differentiation therapy in neuroblastoma.

\section{CELL CYCLE PROGRESSION AND CELL DIFFERENTIATION}

Cell cycle is a series of cellular events that take place during cell division. It consists of four distinct phases: Gap 1 phase (G1 phase), DNA synthesis phase (S phase), Gap 2 phase (G2 phase) and mitosis phase (M phase) ${ }^{[7]}$. The progression through each phase of the cell cycle has been found tightly controlled by a large group of cell cycle-regulating proteins (cell cycle regulators) ${ }^{[8,9]}$. The expression levels and the activities of these cell cycle regulators are tightly controlled and highly coordinated to ensure the normal process of cell growth and division $[10,11]$. Since there is a clear relationship between cell cycle progression and cell differentiation ${ }^{[12-15]}$, it is unsurprising that certain cell cycle regulators or elements have been found to play roles in modulating the cell differentiation process ${ }^{[16-19]}$. More importantly, studies have shown that, for certain cell cycle regulators, manipulating expression level of a single cell cycle regulator is sufficient to induce or block cell differentiation, suggesting that these cell cycle regulators act as independent factors to direct the cell differentiation process. Although the molecular mechanisms by which the cell cycle regulators direct the cell differentiation process are not fully understood, the findings suggest that targeting these cell cycle regulators is an effective approach to differentiation therapy. Here we review the cell cycle regulators that have been found to play key roles in regulating cell differentiation process with an emphasis on neuroblastoma cell differentiation. The cell cycle regulators that we discuss are summarized in the Table 1, and the pathways linking the cell cycle regulators to neuroblastoma cell differentiation are shown in the Fig. 1.

Table 1. Cell cycle regulators that have been linked to neuroblastoma cell differentiation

\begin{tabular}{llllll}
\hline Gene name & $\begin{array}{l}\text { Role in cell } \\
\text { cycle }\end{array}$ & Target & $\begin{array}{l}\text { Expression in } \\
\text { Neuroblastoma }\end{array}$ & $\begin{array}{l}\text { Effect on } \\
\text { differentiation }\end{array}$ & References \\
\hline CDK4/6 & Activate & Rb & Increased & Repress & [16-19] \\
Cyclin D1 & Activate & CDK4 & Increased & Repress & [16-18] \\
p21 & Suppress & CDK2 & Repressed & Induce & [28-30] \\
Rb & Suppress & E2F & Repressed & Induce & [22,23] \\
p27 & Suppress & CDK4 & Increased* & Induce & [26] \\
p57 & Suppress & CDK & & & Repress \\
B-myb & Activate & ND & Increased & R1-33] \\
MYCN & Activate & p21, DKK3, p57, CDKL5 & Gene amplified & Repress & [26] \\
\hline
\end{tabular}


CDKL5 Suppress

Repressed

Induce

[42]

HOXC9

Activate

Cyclin A2, Cyclin B1,

Cyclin B2, CDK1, CDK2

Induce

[40]

Shown are the (1) gene names of the cell cycle regulators, (2) their roles in cell cycle progression, (3) their targets in the cell cycle (4) their expressions in neuroblastoma cells, (5) effect of their overexpression on cell differentiation, and (6) the related references. ${ }^{*}$, the increased p27 is sequestered by CD1. ${ }^{* *}, \mathrm{ND}$, not determined.

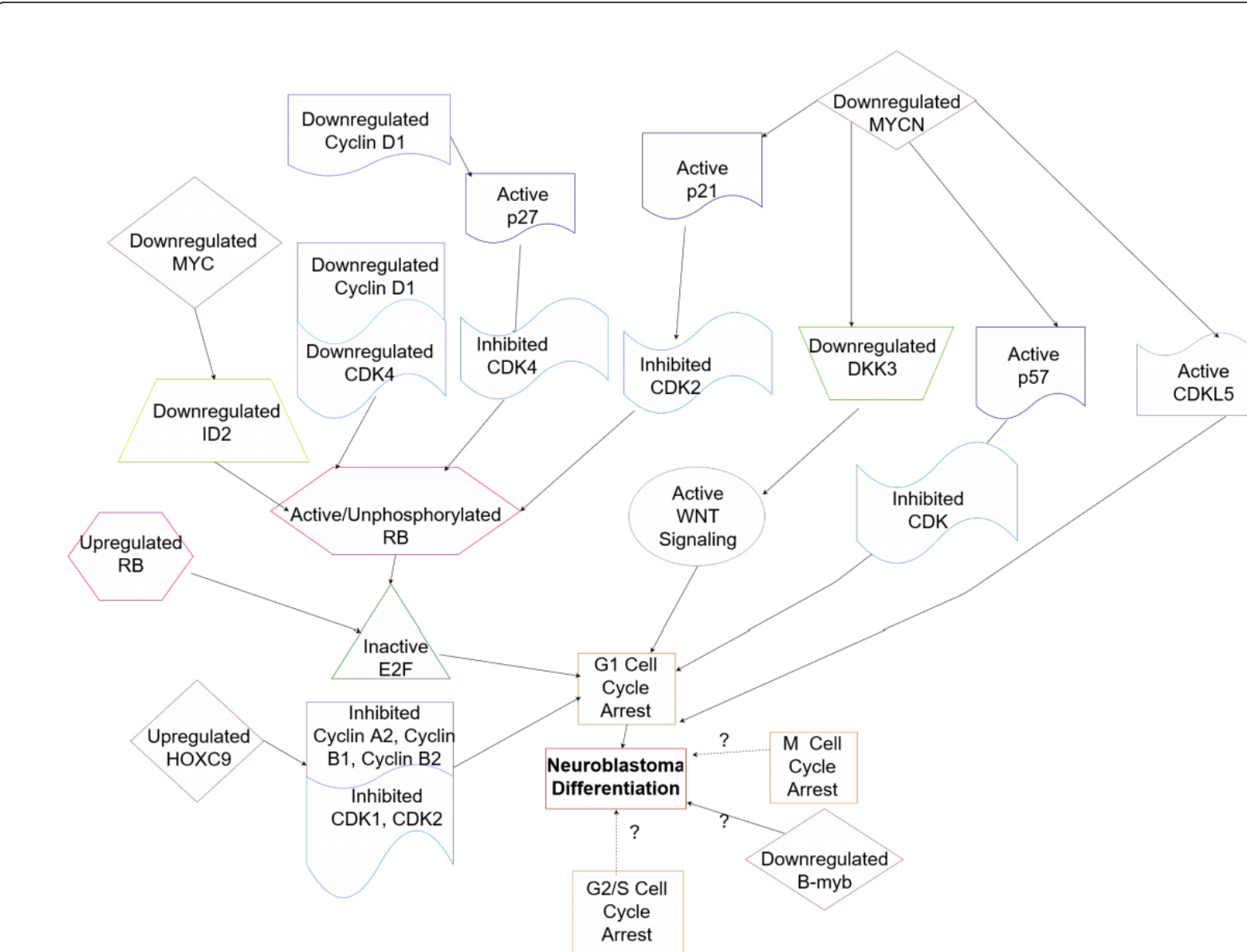

Fig. 1 The relationship between cell cycle progression and differentiation in neruoblastoma cells.

\subsection{CDK4/Cyclin D1 prevent neuroblastoma cell differentiation}

Cyclins and cyclin-dependent kinases (CDKs) have been implicated in influencing cell differentiation. For example, it was shown that cell cycle regulators Cyclin D1 (CD1), D2 and D3 are involved in controlling cell fate in human pluripotent stem cells via recruitment of transcriptional complexes onto neuroectoderm, mesoderm, and endoderm genes ${ }^{[19]}$. Activation of CDK4 and CD1 genes are common in neuroblastoma ${ }^{[20]}$. Overexpression of CDK4 or CD1 has been linked to the undifferentiated neuroblastoma phenotype while downregulation of CDK4/CD1 reduces cell proliferation, induces G1specific cell cycle arrest and significant neuronal 
differentiation ${ }^{[20-23]}$, indicating that CDK4/CD1 act as an independent regulator of neuroblastoma cell differentiation. By exploring the mechanisms underlying the cell differentiation-modulating function of CDK4/CD1, Molenaar et al. found that downregulation of CDK4/CD1 leads to increased level of unphosphorylated retinoblastoma protein $(\mathrm{Rb})^{[6]}$, which inactivates E2F and further results in G1 cell cycle arrest and differentiation ${ }^{[20]}$.

\subsection{Cip/Kip promote neuroblastoma cell differentiation}

Overexpression of Cip/Kip tumor suppressor proteins have been demonstrated to play critical roles in regulating cell cycle progression and development ${ }^{[24-26]}$, suggesting their important role in directing cell differentiation fate. Multiple studies further directly demonstrated their independent role in controlling the cell differentiation fate. For example, p27 overexpression has been found to independently promote neuronal cell differentiation ${ }^{[27]}$. Interestingly, despite being a tumor suppressor, active p27 is overexpressed in some undifferentiated neuroblastoma cells, and it does not exhibit tumor suppressive activity ${ }^{[28]}$; this is due to p27 being sequestered by CD1, and downregulation of CD1 would lead to p27 being activated ${ }^{[28]}$. One possible mechanism by which p27 induces cell differentiation is through inhibiting CDK4 activity, which further lead to de-phosphorylation of $\mathrm{Rb}$. As reviewed above, the unphosphorylated $\mathrm{Rb}$ then inactivates $\mathrm{E} 2 \mathrm{~F}$, resulting in $\mathrm{G} 1$ cell cycle arrest and cell differentiation ${ }^{[20,28]}$. Another possible mechanism is through blocking RhoA signaling by $\mathrm{p} 27^{[27]}$, although the mechanism that $R$ hoA regulates cell differentiation is not fully understood yet. Together with finding reviewed as above, these findings indicate that p27 and CD1 coordinate to control the cell differentiation fate through multiple pathways.

Another Cip/Kip protein that appears to have a role in neuroblastoma differentiation is $\mathrm{p} 21$. It was found that $\mathrm{p} 21$ is downregulated in MYCNamplified neuroblastoma and activated after MYCN is downregulated ${ }^{[29]}$. The activation of $p 21$ is required for survival of differentiating neuroblastoma Cells ${ }^{[30]}$. Possible molecular mechanism underlying p21 activity is through inhibiting CDK2, which further leads to increased level of unphosphorylated $\mathrm{Rb}$ and subsequent inactivation of E2F, resulting in $\mathrm{G} 1$ cell cycle arrest and differentiation ${ }^{[20,30,31]}$. These studies altogether suggest that inhibition of $p 21$ by MYCN may be contributing to the undifferentiated phenotype that is common in MYCN-amplified neuroblastoma.

\subsection{The role of cell cycle regulators in Rb-mediated cell differentiation pathway}

Another tumor suppressor protein family that is involved in regulating both cell cycle progression and cell differentiation is the $\mathrm{Rb}$ protein ${ }^{[6,32]}$. It has been demonstrated that $\mathrm{Rb}$ represses $\mathrm{E} 2 \mathrm{~F}$ transcription, which leads to cell cycle arrest and cell differentiation ${ }^{[33,34]}$. This pathway might play a role in MYCN-mediated cell cycle regulation and cell differentiation pathway. It was also observed that C-MYC downregulation leads to downregulation of an $\mathrm{Rb}$ inhibitor Id2, which subsequent activate $\mathrm{Rb}^{[34]}$.

$\mathrm{Rb}$ may also be involved in regulating neuroblastoma cell differentiation through regulating Bmyb, a transcription factor that has been found to be downregulated during neuroblastomadifferentiation ${ }^{[35-37]}$. It was found that constitutive B-myb expression leads to neuroblastoma cells resistant to differentiation ${ }^{[35]}$, and $\mathrm{Rb}$ was shown to inhibit B-myb expression ${ }^{[38,39]}$. Patient survival analysis showed that B-myb is an independent marker of neuroblastoma prognosis ${ }^{[35]}$. Furthermore, $\mathrm{Rb}$ is a very important tumor suppressor that has been demonstrated to play a role in neuroblastoma tumorigenesis ${ }^{[32,40]}$. The demonstrated role of $\mathrm{Rb}$ in regulating neuroblastoma cell cycle progression and cell differentiation certainly suggest that $\mathrm{Rb}$ is a potential target for differentiation therapy.

\subsection{Other cell cycle regulators potentially involved in neuroblastoma differentiation}

While some cell cycle regulators have been shown to have roles in neuroblastoma celldifferentiation, there are multiple cell cycle regulators that have been found to regulate cell differentiation in other cell types including normal neuronal cells, but not investigated in neuroblastoma. These cell cycle regulators potentially play a role in neuroblastoma cell differentiation and certainly warrant future investigation in neuroblastoma. For example, CDK5 does not act in the same way as other CDKs because CDK5 is not activated by cyclins but instead is activated by complexing with p35, p39 and p67 ${ }^{[41]}$; however, CDK5 has been found to be important in cell cycle control and cell differentiation. For example, CDK5-deficient embryos display loss of cell cycle control and loss of neuronal differentiation ${ }^{[42]}$. Another example Wnt-3a, is a protein involved in Wnt signaling and has been shown to enhance differentiation of neural stem cells into neurons ${ }^{[43]}$. Overall, the findings in neuronal cell differentiation provide additional candidate genes potentially important regulating neuroblastoma 
cell differentiation. Their roles and mechanisms in regulating neuroblastoma cell differentiation certainly warrant investigation in the future.

There are also cell cycle regulators that have been found differentially expressed between differentiated and undifferentiated neuroblastoma cells but have not been directly investigated regarding their role in neuroblastoma cell differentiation. For example, studies showed that HOXC9 is highly overexpressed after retinoic acid treatment, and that overexpression of HOXC9 is correlated with retinoic acid-induced cell differentiation ${ }^{[44]}$. Upregulation of HOXC9 expression has been shown to inhibit multiple cell cycle regulators that have been indicated to play roles in cell differentiation, including CDK1, CDK2, Cyclin $A 2$, Cyclin B1, and Cyclin B2 ${ }^{[44]}$, which suggests that HOXC9 may also be an important regulator of cell differentiation. Further studies are certainly needed to define the role of HOXC9 in cell differentiation especially in neuroblastoma.

\section{THE ROLE OF CELL CYCLE REGULATORS IN MYCN-MEDIATED CELL DIFFERENTIATION PATHWAYS}

A key oncogene that affects activities of cell cycle regulators in neuroblastoma is $\mathrm{MYCN}^{[31]}$. Overexpressed MYCN is associated with very aggressive forms of neuroblastomas. When MYCN is silenced with small interfering RNA, neuroblastoma cells undergo differentiation and apoptosis ${ }^{[45]}$. The mechanism by which MYCN regulates neuroblastoma cell differentiation is still not fully defined. Multiple pathways involving different cell cycle regulators have been found to be important in mediating the differentiation-regulating function of MYCN. For example, one way that MYCN may repress differentiation and cause uncontrollable cell growth is through CDKL5 repression ${ }^{[46]}$. It has been found that inhibition of MYCN activates CDKL5 and leads to $\mathrm{G} 1$ phase arrest and neuroblastoma differentiation ${ }^{[31]}$. CDKL5 is a CDK-like protein that is up-regulated during differentiation in neuroblastoma cells, and it has been found that overexpression of CDKL5 induces differentiation and inhibits proliferation of neuroblastoma cells ${ }^{[46]}$. In another study, in order to systematically identify pathways that MYCN may act through cell cycle regulators, gene expression microarrays were utilized, and it was found that MYCN may promote cell proliferation through regulating expression of two cell cycle regulators, Dickkopf-3 (DKK3) and the tumor suppressor $p 57^{[31]}$. DKK3 is an inhibitor of WNT signaling pathway ${ }^{[47]}$. Knockdown MYCN expression leads to inhibition of DKK3 expression, allowing the WNT signaling pathway to activate, which further induces $\mathrm{G} 1$ cell cycle arrest and differentiation in neuroblastoma cells ${ }^{[31]}$. MYCN knockdown leads to upregulation of $\mathrm{p} 57$ expression ${ }^{[31]}$. p57 has been known to inhibit activities of multiple CDKs including CDK4 and CDK6 ${ }^{[31]}$, which may be one of the underlying differentiation-regulating mechanisms of the MYCN/p57 pathway.

\section{THE ROLE OF HISTONE DEACETYLASES(HDACS) IN REGULATING CELL CYCLE PROGRESSION AND CELL DIFFERENTIATION}

HDACs are a class of enzymes that catalyze the removal of acetyl from an acetylated lysine on a histone protein, allowing the de-acetylated histones to wrap the DNA more tightly, which is an important molecular mechanism to control gene expression. The HDACs have been found to regulate expression of genes that play essential roles in development and development-related diseases ${ }^{[48]}$. HDACs have also been found to play roles in both cell cycle progression and cell differentiation.For example, HDAC1 and HDAC2 are found to be involved in G1-to-S progression by acting together to repress expression of the CDK inhibitors $\mathrm{p} 21$ and $\mathrm{p} 57^{[49]}$. When HADAC1 and HDAC2 are overexpressed, the expression levels of $p 21$ and p57 are decreased, allowing G1-to-S progression; whereas deletion of HDAC1 and HDAC2 in B cells results in G1 arrest and subsequent cell apoptosis. It was further showed that $B$ cells require expression of either HDAC1 or HDAC2 in order to differentiate correctly, since the B cells lacking one or both HDAC1 and HDAC2 did not mature ${ }^{[49]}$. Interestingly, another study showed that HDAC1 is required for differentiation of teratoma cells of mice and humans, and that loss of HDAC1 is linked to increased apoptosis ${ }^{[50]}$. It is also reported that HDAC1 presents in high levels in differentiated cells, while HDAC2 is overexpressed in undifferentiated samples of teratoma ${ }^{[50]}$. These studies altogether suggest that imbalance of HDAC1 and HDAC2 expression levels may be a key factor that contribute to differentiation-related diseases including neuroblastoma.

Another HDAC of interest is HDAC7, which has 
been linked to cancer cell progression via regulation of c-Myc expression. Silencing HDAC7 could lead to $\mathrm{G} 1$ cell cycle arrest, which is likely caused by the significantly decreased expression of c-Myc [51], a regulator of both cell cycle progression and differentiation ${ }^{[52]}$. HDAC8 is another HDAC that has been investigated in neuroblastoma ${ }^{[53]}$. It was showed that selective HDAC8 inhibitors had antineuroblastoma activity and little toxicity effects in mouse xenografted MYCN-amplified neuroblastoma models while non-selective HDAC8 inhibitors were observed more toxicity in these models. Combination these inhibitors with retinoic acid induced significant neurite outgrowth and cell differentiation ${ }^{[53]}$, suggesting that HDAC8 may be also involved in the differentiation pathway of neuroblastoma cells.

\section{TARGETING THE DIFFERENTIATION-CONTROLLING CELL CYCLE REGULATORS AS DIFFERENTIATION THERAPY}

Targeting cell cycle progression has been demonstrated to be an effective approach of treating cancer. Knowledge on the role of specific cycle regulators in regulating cell differentiation suggests the potential of developing differentiation therapy by targeting differentiation-controlling cell cycle regulators. In fact, certain currently discovered differentiation agents have been found to modulate expression of cell cycle regulators that are independent modulators of cell differentiation, suggesting one of the differentiation-inducing mechanisms underlying these differentiation agents is through downregulating expression or activities of cell cycle regulators. For example, combination of vitamin K2 with cotylenin A were used to induce differentiation of leukemia cells ${ }^{[54]}$, which was accompanied by upregulated expression of cyclin G2 and induced G1 phase arrest. Treating leukemia cells with gambogic acid resulted in cell growth inhibition and differentiation, which was associated with upregulated $\mathrm{p} 21^{[55]}$. Eupatilin has been found to induce cell cycle arrest and differentiation in gastric carcinoma along with activation of p21 ${ }^{[56]}$. Another example is 4-amino-2-trifluromethylphenyl retinate (ATPR), which is a derivative of alltrans retinoic acid (ATRA) and has been shown to induce both cell differentiation and G0/G1 phase arrest in gastric adenocarcinoma cells ${ }^{[57]}$. This is relevant to neuroblastoma because, as a derivative of ATRA, ATPR may represent an alternative for neuroblastoma patients who have developed resistance to retinoic acid.
On the other hand, therapeutic drug candidates that were developed to target cell cycle progression have been found to induce cell differentiation. For example, cycloheximide was found to induce $\mathrm{G} 1$ and $S$ phases arrest by repressing expression of Cyclin D1 with morphological changes that indicated cell differentiation in glioma cells ${ }^{[58]}$. A small molecule CG500354, which has been shown to target cell cycle regulators p53, p21, and p27 in glioblastoma cells ${ }^{[59]}$, was found to induce glioblastoma cell differentiation ${ }^{[59]}$. These studies are relevant to neuroblastoma because glioblastoma was thought to arise from neural stem cells in a similar manner with neuroblastoma ${ }^{[60]}$. HDAC inhibitors have been developed to treat multiple types of cancers. HDAC inhibitors potentially could be used as differentiation agents to treat neuroblastoma since HDACs are heavily involved in both cell cycle regulation and cell differentiation. One study showed that glioblastoma cells treated with a HDAC inhibitor, valproic acid, resulted in induced expression of p21 along with upregulated expression of the glial differentiation marker ${ }^{[61]}$, suggesting the promise of applying selective HDAC inhibitors as differentiation agents for treating cancer.

High-throughput approaches for identifying substances that affect cell cycle progression and induce neuroblastoma cell differentiation have been developed separately ${ }^{[62,63]}$. The combination of these two arms of screening approaches can be used to identify differentiation-inducing candidates that target cell cycle regulators. Plant extracts are excellent sources for applying the combined two arms of screening, since compounds that induce both cell cycle arrest and differentiation have been identified from plant extracts. For example, aqueous ethanolic extract of Tinospora cordifolia has been identified to induce neuroblastoma cell arrest in G1 phase. The treated neuroblastoma cells show altered expression of cyclin D1 and cell differentiation ${ }^{[64]}$. In another study, treatment with the antioxidant extracts of African medicinal plants induces cell cycle arrest due to increased expression of p53, p21, and p27 protein levels; and it is capable of inducing differentiation of the melanoma cells as shown by the growth of cytoplasmic dendrites ${ }^{[65]}$, suggesting the potential to identify differentiation agents from these plants. 5,7-dimethoxycoumarin, a compound isolated from leaves and fruits of Pelea anisata H. Mann, induces cell cycle arrest in $\mathrm{G} 1$ phase and cell differentiation rather than killing the melanoma cells ${ }^{[66]}$. This finding is potentially relevant to neuroblastoma because both melanoma and neuroblastoma are neuroendocrine cancers ${ }^{[67]}$. Another plant extract found to have differentiation inducing effects is omacetaxine mepesuccinate ${ }^{[68]}$. The effects of this alkaloid was studied using diffuse large B-cell 
lymphoma cells and was found to include apoptosis in these lymphoma cells along with G0/G1 phase cell cycle arrest. The alkaloid was also capable of inducing cell differentiation in the lymphoma cells as shown by expression of antigens commonly associated with differentiated lymphocytes. This alkaloid acts by increasing expression of p27 and p21 leading to $\mathrm{G} 1$ cell cycle arrest ${ }^{[68]}$. Another study found that extracts obtained from sea buckthorn, dog rose, sage, and oregano were capable of reducing proliferation and viability in leukemia cells they did not outright induce differentiation ${ }^{[69]}$. Instead the extracts were found to increase the effect of differentiation induced by a hormonal vitamin D. Cell cycle analysis of acute myeloid leukemia cells treated with these extracts showed that there was partial S-phase arrest along with reduced levels of cyclins $A$ and $E$ and upregulated $p 27$. This study shows that while these extracts may not be sufficient to induce differentiation, they can increase the effects of differentiation drugs that may have not been as effective ${ }^{[69]}$. In addition to plant extracts, there may be differentiation-inducing agents in the form of traditional Chinese medicine such as Pien
Tze Haung $(\mathrm{PTH})^{[70]}$. PTH is a Chinese herbal medicine which has shown anticancer activities in colorectal cancer and cancer stem cells arising from this cancer. This study focuses on the effect of PTH on colorectal cancer stem cells. Cells treated with PTH underwent apoptosis, decreased proliferation, and were found to be differentiated ${ }^{[70]}$. The activity of PTH in colorectal cancer stem cells was suggested to be a result of inhibited Notch signaling which has been linked to cancer stem cell survival in the past ${ }^{[70]}$.

In summary, studies have identified many synthetic and natural compounds that target differentiation-modulating cell cycle regulators (Table 2), suggesting the promise to develop these compounds as novel differentiation agents for treating neuroblastoma. Given the constant effort of developing cost-effective high-throughput approaches to drug discovery, the identification of novel differentiation agents that target cell cycle progression from various sources including plants, is becoming practical. We expect that additional novel effective differentiation agents that target cell cycle regulators will be identified in the near future.

Table 2. Differentiation agents that regulate expression/activities of cell cycle regulators

\begin{tabular}{|c|c|c|c|c|}
\hline Agent & Cancer & Target & Effect & Reference \\
\hline Vitamin K2 with cotylenin A & Leukemia & Cyclin G2 & Upregulated & 54 \\
\hline Gambogic acid & Leukemia & Cyclin G2 & Upregulated & 55 \\
\hline Eupatilin & Gastric carcinoma & p21 & Activation & 56 \\
\hline ATPR & Gastric carcinoma & $\mathrm{p} 27$ & Upregulated & 57 \\
\hline Cycloheximide & Glioblastoma & Cyclin D1 & Repressed & 58 \\
\hline CG500354 & Glioblastoma & p53, p21, p27 & Upregulated & 59 \\
\hline Valproic acid & Glioblastoma & p21 & Upregulated & 61 \\
\hline Tinospora cordifolia extract & Neuroblastoma & Cyclin D1 & Downregulated & 64 \\
\hline African medicinal plant extract & Neuroblastoma & p53, p21, p27 & Upregulated & 65 \\
\hline 5, 7-dimethoxycoumarin & Melanoma & $\begin{array}{l}\text { Ras/Raf/MEK/ERK } \\
\text { Map kinase pathway }\end{array}$ & Inhibition & 66 \\
\hline Omacetaxin mepesuccinate & Lymphoma & $\mathrm{p} 27, \mathrm{p} 21$ & Upregulated & 68 \\
\hline $\begin{array}{l}\text { Sea buckthorn, dog rose, sage, } \\
\text { oregano extracts }\end{array}$ & Leukemia & Cylcin A and E p27 & $\begin{array}{l}\text { Downregulated } \\
\text { Upregulated }\end{array}$ & 69 \\
\hline Pien Tze Haung & $\begin{array}{l}\text { Colorectal cancer } \\
\text { stem cells }\end{array}$ & Notch1 & Inhibition & 70 \\
\hline
\end{tabular}

Shown are the (1) name of differentiation agent, (2) type of cancers investigated in, (3) cell cycle genes regulated by the corresponding agent, (4) the corresponding regulatory effect on cell cycle genes, and (5) the related references. 


\section{CONCLUSSION}

In summary, cell cycle progression and cell differentiation are tightly coupled cellular processes. More importantly, multiple cell cycle regulators have been found to function as independent regulators of the cell differentiation fate in various cell types including neuroblastoma cells. However, the exact mechanisms underlying the differentiation-regulating function of these cell cycle regulating proteins are not fully understood. Future studies are certainly needed to further define the molecular pathways that bridge the cell cycle progression and cell differentiation, which will provide further guidance for developing differentiation agents that specifically target cell cycle. Furthermore, it is interesting that all the cell cycle regulators that are found to regulate cell differentiation are regulators of $\mathrm{G} 1 / \mathrm{S}$ phase (Fig.1). Whether some of the regulators of other phases could act as independent regulators of cell differentiation is an interesting question and certainly warrants further investigation.

Differentiation-inducing agents that target cell cycle regulators have been discovered. However, their therapeutic potential as differentiation agents has not been fully evaluated, and there is currently a lack of further investigation of their therapeutic potential in pre-clinical and clinical models. However, this is certainly a promising strategy to develop new differentiation therapies for neuroblastomas that are resistant to current differentiation agents. Future therapeutic studies are certainly warranted. In addition, given the recent progress in developing high-throughput screening approaches for identifying substance that alters cell cycle progression and induces cell differentiation, we expect that additional new differentiation agents that target cell cycle progression will be identified from various of drug sources in the near future.

\section{REFERENCES}

1. Ward E, Desantis C, Robbins A, Kohler B, Jemal A. Childhood and adolescent cancer statistics, 2014. CA: A Cancer J Clin. 2014;64(2):83-103.

2. Maris JM, Hogarty MD, Bagatell R, Cohn SL. Neuroblastoma. Lancet. 2007;369(9579):21062120.

3. Brodeur GM. Neuroblastoma: biological insights into a clinical enigma. Nat Rev Cancer. 2003;3(3):203-216.

4. Cruz FD, Igor M. Solid Tumor Differentiation Therapy-Is it Possible? Oncotarget.
2015;3(5):559-567.

5. Matthay KK. Neuroblastoma. Nat Rev Dis Primers. 2016;2:16078.

6. Matthay KK, Reynolds CP, Seeger RC, Shimada $H$, Adkins ES, Haas-Kogan D, Gerbing RB, London WB, Villablanca JG. Long-term results for children with high-risk neuroblastoma treated on a randomized trial of myeloablative therapy followed by 13-cis-retinoic acid: a children's oncology group study. J Clin Oncol. 2009;27(7):1007-1013.

7. Vermeulen K, Van Bockstaele DR, Berneman ZN. The cell cycle: a review of regulation, deregulation and therapeutic targets in cancer. Cell Prolif. 2003; 36 (3): 131-149.

8. Buttitta LA, Edgar BA. Mechanisms controlling cell cycle exit upon terminal differentiation. Curr Opin Cell Biol. 2007;19(6):697-704.

9. Harper JW, Elledge SJ. Cdk inhibitors in development and cancer. Curr Opin Genet Dev. 1996;6(1):56-64.

10. Li VC, Kirschner MW. Molecular ties between the cell cycle and differentiation in embryonic stem cells. Proc Natl Acad Sci USA. 2014;111(26):9503-9508.

11. Reichert $H$. Drosophila neural stem cells: cell cycle control of self-renewal, differentiation, and termination in brain development. Results Probl Cell Differ. 2011;53:529-546.

12. Soufi A, Dalton S. Cycling through developmental decisions: how cell cycle dynamics control pluripotency, differentiation and reprogramming. Development. 2016;143(23):4301-4311.

13. Ruijtenberg $S$, van den Heuvel $S$. Coordinating cell proliferation and differentiation: Antagonism between cell cycle regulators and cell typespecific gene expression. Cell Cycle. 2016;15(2):196-212.

14. Hardwick LJ, Ali FR, Azzarelli R, Philpott A. Cell cycle regulation of proliferation versus differentiation in the central nervous system. Cell Tissue Res. 2015;359(1):187-200.

15. Maeda Y. Cell-cycle checkpoint for transition from cell division to differentiation. Dev Growth Differ. 2011;53(4):463-481.

16. Liu L, Michowski W, Inuzuka H, Shimizu K, Nihira NT, Chick JM, Li N, Geng Y, Meng AY, Ordureau A, Kolodziejczyk A, Ligon KL, Bronson RT, Polyak K, Harper JW, Gygi SP, Wei W, Sicinski P. G1 cyclins link proliferation, pluripotency and differentiation of embryonic stem cells. Nat Cell Biol. 2017;19(3):177-188. 
17. Hydbring $P$, Malumbres $M$, Sicinski P. Noncanonical functions of cell cycle cyclins and cyclin- dependent kinases. Nat Rev Mol Cell Biol. 2016;17(5):280-292.

18. Miles A, Tropepe V. Coordinating progenitor cell cycle exit and differentiation in the developing vertebrate retina. Neurogenesis (Austin). 2016;3(1):e1161697.

19. Pauklin S, Madrigal $P$, Bertero A, Vallier L. Initiation of stem cell differentiation involves cell cycle-dependent regulation of developmental genes by Cyclin D. Genes Development. 2016;30(4):421-433.

20. Molenaar JJ, Ebus ME, Koster J, van Sluis $P$, van Noesel CJ, Versteeg R, Caron HN. Cyclin D1 and CDK4 activity contribute to the undifferentiated phenotype in neuroblastoma. Cancer Res. 2008; 68(8):2599-2609.

21. Easton J, Wei T, Lahti JM, Kidd VJ. Disruption of the cyclin D/cyclin-dependent kinase/INK4/ retinoblastoma protein regulatory pathway in human neuroblastoma. Cancer Res. 1998;58(12):2624-2632.

22. Magro G, Salvatorelli L, Di Cataldo A, Musumeci G, Spoto G, Parenti R. Cyclin D in human neuroblastic tumors recapitulates its developmental expression: An immunohistochemical study. Acta Histochem. 2015;117(4-5):415-424.

23. Gogolin S, Ehemann V, Becker G, Brueckner LM, Dreidax D, Bannert S, Nolte I, Savelyeva L, Bell E, Westermann F. CDK4 inhibition restores $\mathrm{G}(1)-\mathrm{S}$ arrest in MYCN-amplified neuroblastoma cells in the context of doxorubicin-induced DNA damage. Cell Cycle. 2013;12(7):1091-1104.

24. Besson A, Dowdy SF, Roberts JM. CDK inhibitors: cell cycle regulators and beyond. Dev Cell. 2008;14 (2):159-169.

25. Nakayama K, Nakayama K. Cip/Kip cyclindependent kinase inhibitors: Brakes of the cell cycle engine during development. Bioessays. 1999;20(12):1020-1029.

26. Carruthers S, Mason J, Papalopulu N. Depletion of the cell-cycle inhibitor p27(Xic1) impairs neuronal differentiation and increases the number of ElrC (+) progenitor cells in Xenopus tropicalis. Mech Dev. 2003;120(5):607-616.

27. Nguyen L, Besson A, Heng JI, Schuurmans C, Teboul L, Parras C, Philpott A, Roberts JM, Guillemot F. p27kip1 independently promotes neuronal differentiation and migration in the cerebral cortex. Genes Dev. 2006;20(11):15111524.
28. Munoz JP, Sanchez JR, Maccioni RB. Regulation of p27 in the process of neuroblastoma N2A differentiation. J Cell Biochem. 2003;89(3):539549.

29. Iraci N, Diolaiti D, Papa A, Porro A, Valli E, Gherardi S, Herold S, Eilers M, Bernardoni R, Della Valle G, Perini G. A SP1/MIZ1/MYCN repression complex recruits HDAC1 at the TRKA and p75NTR promoters and affects neuroblastoma malignancy by inhibiting the cell response to NGF. Cancer Res. 2011;71(2):404412.

30. Poluha W, Poluha DK, Chang B, Crosbie NE, Schonhoff CM, Kilpatrick DL, Ross AH. The cyclin-dependent kinase inhibitor p21 (WAF1) is required for survival of differentiating neuroblastoma cells. Mol Cell Biol. 1996;16(4):1335-1341.

31. Bell E, Lunec J, Tweddle DA. Cell cycle regulation targets of $M Y C N$ identified by gene expression microarrays. Cell Cycle. 2007;6(10):1249-1256.

32. Markaki EA, Tsopanomichalou M, Dimitriou H, Stiakaki E, Perdikoyanni C, Spandidos D, Kalmanti M. Mutations of retinoblastomagene $(\mathrm{Rb}-1)$ as a prognostic factor in children with acute leukemia and neuroblastoma. Pediatr Hematol Oncol. 2001;18(2):101-110.

33. Ross JF, liu X, Dynlacht BD. Mechanism of Transcriptional Repression of E2F by the Retinoblastoma Tumor Suppressor Protein. Mol Cell. 1999;3(2):195-205.

34. Lasorella A, Noseda M, Beyna M, Yokota Y, lavarone A. Id2 is a retinoblastoma protein target and mediates signalling by Myc oncoproteins. Nature. 2000;407(6804):592-598.

35. Raschellà G, Cesi V, Amendola R, Negroni A, Tanno B, Altavista P, Calabretta B. Expression of B-myb in Neuroblastoma Tumors is a Poor Prognostic Factor Indepedent from MYCN Amplification. Cancer Res. 1999;59:3365-3368.

36. Lasorella A, Noseda M, Beyna M, lavarone A. Id2 is a retinoblastoma protein target and mediates signalling by Myc oncoproteins. Nature. 2000;407:592-598.

37. Raschellà G, Negroni A, Pucci S, Amendola R, Valeri S, Calabretta B. B-myb Transcriptional Regulation and mRNA Stability during Differentiation of Neuroblastoma Cells. Exp Cell Res. 1996;222(2):395-399.

38. Raschellà G, Tanno B, Bonetto F, Negroni A, Claudio PP, Baldi A, Amendola R, Calabretta B, Giordano A, Paggi MG. The RB-related gene 
$\mathrm{Rb} 2 / \mathrm{p} 130$ in neuroblastoma differentiation and in B-myb promoter down-regulation. Cell Death Differ. 1998;5(5):401-407.

39. Raschellà G, Tanno B, Bonetto F, Negroni A, Amendola R, Paggi MG. Retinoblastoma family proteins induce differentiation and regulate B-myb expression in neuroblastoma cells. Med Pediatr Oncol. 2001;36(1):104-107.

40. Wallick CJ, Gamper I, Thorne M, Feith DJ, Takasaki KY, Wilson SM, Seki JA, Pegg AE, Byus CV, Bachmann AS. Key role for p27Kip1, retinoblastoma protein $\mathrm{Rb}$, and $\mathrm{MYCN}$ in polyamine inhibitor-induced $\mathrm{G} 1$ cell cycle arrest in MYCN-amplified human neuroblastoma cells. Oncogene. 2005;24(36):5606-5618.

41. Amin ND, Albers W, Pant HC. Cyclin-dependent kinase 5 (cdk5) activation requires interaction with three domains of p35. J Neurosci Res. 2002;67(3):354-362.

42. Cicero S. and Herrup K. Cyclin-Dependent Kinase 5 Is Essential for Neuronal Cell Cycle Arrestand Differentiation. J Neurosci. 2005;25(42):9658-9668.

43. Muroyama $\mathrm{Y}$, Kondoh H, Takada S. Wnt proteins promote neuronal differentiation in neural stem cell culture. Biochem Biophys Res Commun. 2004;313(4):915-921.

44. Mao L, Ding J, Zha Y, Yang L, McCarthy BA, King W, Cui H, Ding HF. HOXC9 links cellcycle exit and neuronal differentiation and is a prognostic marker in neuroblastoma. Cancer Res. 2011;71(12):4314-4324.

45. Kang JH, Rychahou PG, Ishola TA, Qiao J, Evers BM, Chung DH. MYCN silencing induces differentiation and apoptosis in human neuroblastoma cells. Biochem Biophys Res Commun. 2006;351(1):192-197.

46. Valli E1, Trazzi S, Fuchs C, Erriquez D, Bartesaghi R, Perini G, Ciani E. CDKL5, a novel MYCN-repressed gene, blocks cell cycle and promotes differentiation of neuronal cells. Biochim Biophys Acta. 2012;1819(11-12):11731185.

47. Veeck J, Dahl E. Targeting the Wnt pathway in cancer: the emerging role of Dickkopf-3. Biochim Biophys Acta. 2012;1825(1):18-28.

48. Haberland M, Montgomery RL, OIson EN. The many roles of histone deacetylases in development and physiology: implications for disease and therapy. Nat Rev Genet. 2009;10(1):32-42.

49. Yamaguchi T, Cubizolles F, Zhang Y, Reichert
$\mathrm{N}$, Kohler H, Seiser C, Matthias P. Histone deacetylases 1 and 2 act in concert to promote the G1-to-S progression. 2010;24(5):455-469.

50. Lagger S, Meunier D, Mikula M, Brunmeir R, Schlederer M, Artaker M, Pusch O, Egger G, Hagelkruys A, Mikulits W, Weitzer G, Muellner EW, Susani M, Kenner L, Seiser C. Crucial function of histone deacetylase 1 for differentiation of teratomas in mice and humans. EMBO J. 2010;29(23):3992-4007.

51. Zhu C, Chen Q, Xie Z, Ai J, Tong L, Ding J, Geng M. The role of histone deacetylase 7 (HDAC7) in cancer cell proliferation: regulation on C-Myc. J Mol Med (Berl). 2011;89(3):279-289.

52. Lin KI, Lin Y, Calame K. Repression of c-myc is necessary but not sufficient for terminal differentiation of $B$ lymphocytes in vitro. Mol Cell Biol. 2000;20(23):8684-8695.

53. Rettig I, Koeneke E, Trippel F, Mueller WC, Burhenne J, Kopp-Schneider A, Fabian J, Schober A, Fernekorn U, von Deimling A, Deubzer HE, Milde T, Witt O, Oehme I. Selective inhibition of HDAC8 decreases neuroblastoma growth in vitro and in vivo and enhances retinoic acid-mediated differentiation. Cell Death Dis. 2015;6:e1657.

54. Maniwa Y, Kasukabe T, Kumakura S. Vitamin K2 and cotylenin A synergistically induce monocytic differentiation and growth arrest along with the suppression of c-MYC expression and induction of cyclin G2 expression in human leukemia HL60 cells. Int J Oncol. 2015;47(2):473-480.

55. Chen Y, Hui H, Li Z, Wang HM, You QD, Lu N. Gambogic acid induces growth inhibition and differentiation via upregulation of p21waf1/cip1 expression in acute myeloid leukemia cells. J Asian Nat Prod Res. 2014;16(10):1000-1008.

56. Choi EJ, Oh HM, Wee H, Choi CS, Choi SC, Kim $\mathrm{KH}$, Han WC, Oh TY, Kim SH, Jun CD. Eupatilin exhibits a novel anti-tumor activity through the induction of cell cycle arrest and differentiation of gastric carcinoma AGS cells. Differentiation. 2009;77(4):412-423.

57. Xia Q, Zhao Y, Wang J, Qiao W, Zhang D, Yin $\mathrm{H}, \mathrm{Xu} \mathrm{D}$, Chen F. Proteomic analysis of cell cycle arrest and differentiation induction caused by ATPR, a derivative of all-trans retinoic acid, in human gastric cancer SGC-7901 cells. Proteomics Clin Appl. 2017.

58. Liu X, Yang JM, Zhang SS, Liu XY, Liu DX. Induction of cell cycle arrest at $\mathrm{G} 1$ and $S$ phases and CAMP-dependent differentiation in $\mathrm{C} 6$ glioma by low concentration of cycloheximide. 
BMC Cancer. 2010;10:684.

59. Kang TW, Choi SW, Yang SR, Shin TH, Kim HS, Yu KR, Hong IS, Ro S, Cho JM, Kang KS. Growth arrest and forced differentiation of human primary glioblastoma multiforme by a novel small molecule. Sci Rep. 2014;4:5546.

60. de Weille J. On the Genesis of Neuroblastoma and Glioma. Int J Brain Sci. 2014;2014:14.

61. Das CM, Aguilera D, Vasquez H, Prasad P, Zhang M, Wolff JE, Gopalakrishnan V. Valproic acid induces p21 and topoisomerase-II (alpha/ beta) expression and synergistically enhances etoposide cytotoxicity in human glioblastoma cell lines. J Neurooncol. 2007;85(2):159-170.

62. Blasi T, Hennig $H$, Summers HD, Theis FJ, Cerveira J, Patterson JO, Davies D, Filby A, Carpenter AE, Rees P. Label-free cell cycle analysis for high-throughput imaging flow cytometry. Nat Commun. 2016;7:10256.

63. Zhao Z, Ma X, Hsiao TH, Lin G, Kosti A, Yu X, Suresh U, Chen Y, Tomlinson GE, Pertsemlidis A, Du L. A high-content morphological screen identifies novel microRNAs that regulate neuroblastoma cell differentiation. Oncotarget. 2014;5(9):2499-2512.

64. Mishra R, Kaur G. Tinospora cordifolia Induces Differentiation and Senescence Pathways in Neuroblastoma Cells. Mol Neurobiol. 2015;52(1): 719-733.

65. Gismondi A, Canuti L, Impei S, Di Marco G, Kenzo M, Colizzi V, Canini A. Antioxidant extracts of African medicinal plants induce cell cycle arrest and differentiation in B16F10 melanoma cells. Int J Oncol. 2013;43(3):956964.

66. Alesiani D, Cicconi R, Mattei M, Montesano C,Bei $\mathrm{R}$, Canini A. Cell cycle arrest and differentiation induction by 5,7-dimethoxycoumarin in melanoma cell lines. Int J Oncol. 2008; 32(2):425-434.

67. Murphy GF, Wilson BJ, Girouard SD, Frank NY, Frank MH. Stem Cells and Targeted Approaches to Melanoma Cure. Mol Aspects Med. 2014;39:33-49.

68. Zhang L, Chen Z, Zuo W, Zhu X, Li Y1, Liu X, Wei $X$. Omacetaxine mepesuccinate induces apoptosis and cell cycle arrest, promotes cell differentiation, and reduces telomerase activity in diffuse large Bcell lymphoma cells. Mol Med Rep. 2016;13(4):3092-3100.

69.Zhamanbayeva GT, Aralbayeva AN, Murzakhmetova MK, Tuleukhanov ST, Danilenko M. Cooperative antiproliferative and differentiation-enhancing activity of medicinal plant extracts in acute myeloid leukemia cells. Biomed Pharmacother. 2016;82:80-89.

70. Qi F, Wei L, Shen A, Chen Y, Lin J, Chu J, Cai Q, Pan J, Peng J. Pien Tze Huang inhibit the proliferation, and induces the apoptosisand differentiation of colorectal cancer stem cells via suppression of the Notch1 pathway. Oncol Rep. 2016;35(1):511-517. 